\title{
Two Versions of Life: Emotionally Negative and Positive Life Events Have Different Roles in The Organization of Life Story and Identity
}

\author{
Dorthe Berntsen \\ Center on Autobiographical Memory Research, Aarhus \\ University
}

\author{
David C. Rubin \\ Duke University and Center on Autobiographical Memory \\ Research, Aarhus University
}

\author{
Ilene C. Siegler \\ Duke University School of Medicine and Duke University
}

\begin{abstract}
Over 2,000 adults in their sixties completed the Centrality of Event Scale (CES) for the traumatic or negative event that now troubled them the most and for their most positive life event, as well as measures of current PTSD symptoms, depression, well-being, and personality. Consistent with the notion of a positivity bias in old age, the positive events were judged to be markedly more central to life story and identity than were the negative events. The centrality of positive events was unrelated to measures of PTSD symptoms and emotional distress, whereas the centrality of the negative event showed clear positive correlations with these measures. The centrality of the positive events increased with increasing time since the events, whereas the centrality of the negative events decreased. The life distribution of the positive events showed a marked peak in young adulthood whereas the life distribution for the negative events peaked at the participants' present age. The positive events were mostly events from the cultural life script - that is, culturally shared representations of the timing of major transitional events. Overall, our findings show that positive and negative autobiographical events relate markedly differently to life story and identity. Positive events become central to life story and identity primarily through their correspondence with cultural norms. Negative events become central through mechanisms associated with emotional distress.
\end{abstract}

Keywords: autobiographical memory, emotion, positivity bias, trauma, cultural life script

One important component of an emotional experience is whether it is perceived as positive or negative and, thus, experienced as beneficial or detrimental to a person's well-being. Somewhat surprisingly, when individual properties of autobiographical memories are studied, typically few reliable effects of emotional valence are seen. Studies examining memory for emotionally positive versus negative events have generally shown that their associated intensity (or arousal) is a much stronger predictor for their characteristics than their valence

This article was published Online First August 29, 2011

Dorthe Berntsen, Department of Psychology, Center on Autobiographical Memory Research, Aarhus University, Aarhus, Denmark; David C. Rubin, Department of Psychology and Neuroscience, Duke University and Center on Autobiographical Memory Research, Aarhus University; Ilene C. Siegler, Department of Psychiatry and Behavioral Sciences, Duke University School of Medicine and Duke University.

This work was supported by funding from the National Institute of Mental Health Grant R01 MH066079, from the Danish Council for Independent Research: Humanities (273-08-02590), from the Danish National Research Foundation (Centre of Excellence program). The UNC Alumni Heart Study is supported by Grant R01 HL55356 from the National Heart Lung and Blood Institute with cofunding from the National Institute on Aging and the Duke Behavioral Medicine Research Center.

Correspondence concerning this article should be addressed to Dorthe Berntsen, Department of Psychology, Center on Autobiographical Memory Research, Aarhus University, Nobelparken, Jens Chr. Skousvej 4, 8000 Aarhus C. Denmark. E-mail: dorthe@psy.au.dk (e.g., Bradley, Greenwald, Petry, \& Lang, 1992; Reisberg, Heuer, McLean, \& O'Shaughnessy, 1988; Talarico, LaBar, \& Rubin, 2004), although some effects of valence are seen, notably concerning accuracy (e.g., Bohn \& Berntsen, 2007; Kensinger \& Schacter, 2006) and level of details (e.g., Berntsen, 2002; Fredrickson \& Branigan, 2005; Talarico, Berntsen, \& Rubin, 2009; see Holland \& Kensinger, 2010, for review).

In contrast, when the long-term accessibility of emotional memories is examined, powerful effects of emotional valence are seen, consistent with the view that positive and negative affectivity form two different, and relatively independent, systems (see Gilboa \& Revelle, 1994, for a review). Here we add to this literature by examining how central highly positive versus highly negative events are perceived to be for the person's life-story and identity in a large sample of older adults. This narrative property of individual recollections has been largely overlooked in research addressing the effects of emotion on autobiographical memory. However, it is a predictor for the long-term accessibility of emotional memories (Berntsen \& Bohn, 2010) and related to emotional distress (Berntsen \& Rubin, 2006; Berntsen \& Rubin, 2007). Following the literature on emotion and personality, we also expect the centrality of positive versus negative memories to interact with measures of personality traits, such as extraversion and neuroticism (e.g., Gilboa \& Revelle, 1994).

We examine the centrality of positive and negative autobiographical events in a sample of over 2,000 adults in their sixties, 
using the Centrality of Event Scale (CES; Berntsen \& Rubin, 2006, 2007), which taps the extent to which a memory is seen as central to the person's life story and identity. We also obtained measures of PTSD symptoms, other indicators of distress and well-being as well as measures of personality. This allows us to examine whether centrality ratings for the negative and positive events differ overall and whether such possible difference interacts with level of emotional distress as well as personality. By involving a large sample of adults in their sixties and by asking them to date when the events took place, we are able to examine whether the centrality of the negative and positive events vary for events happening at different times across the life span. In the following we review the literature.

\section{Effects of Emotional Valence on The Long-Term Accessibility of Autobiographical Memories}

The effects of emotional valence on the long-term accessibility of autobiographical events are profound. These effects, to be reviewed, concern (a) the frequency and retrieval time of emotionally positive and negative memories, (b) the distribution of emotionally positive and negative memories over the life span, (c) the effects of emotional disorders on the accessibility of positive and negative memories, and (d) the effects of personality on the accessibility of positive and negative memories.

\section{Frequency and Retrieval Time of Emotionally Positive and Negative Memories}

Across multiple studies using different sampling techniques, emotionally positive autobiographical memories are about twice as frequent as are negative autobiographical memories (Walker, Skowronski, \& Thompson, 2003, for review). Positive events also have shorter retrieval times as compared to negative events (Lishman, 1974), again suggesting that the former are more accessible. The increased accessibility of positive relative to negative events may in part reflect that people encounter more positive than negative events in their lives or, at least, that they choose to interpret more events as being overall positive rather than negative. However, because mood induction manipulations have been found to affect the frequency and pace with which positive versus negative memories are recalled (see Williams, 1992, for review), some of the advantages of positive events are most likely due to biases of memory. Also supporting this memory-bias view is the finding that the perceived emotional intensity of emotionally negative events fades more quickly in memory than does the perceived intensity of positive memories (see Walker, Skowronski, \& Thompson, 2003, for a review). This fading affect bias has been found in retrospective as well as in prospective studies. In a prospective study by Walker, Vogl, and Thompson (1997), subjects recorded personal events in a diary and subsequently rated the intensity of the associated emotion at a 3 months, 1 year, and 4.5 years delay. The intensity ratings of both positive and negative emotion dropped over time, but the decline was faster for emotionally negative than for emotionally positive memories.

One reason for the enhanced accessibility of emotionally positive autobiographical information and the fading affect bias may be different rehearsal patterns for differently valenced material. Walker, Skowronski, Gibbons, Vogl, \& Ritchie (2009) found that positive events tend to be more rehearsed than negative events, across different types of rehearsal. They also found rehearsal to be generally negatively related to the fading of emotional intensity.

The tendency to recall more emotionally positive than negative events is enhanced in old age, suggesting that emotion regulation through selective encoding and remembering is more common among old than among young adults (e.g., Kennedy, Mather, \& Carstensen, 2004; Schlagman, Schulz, \& Kvavilashvili, 2006). This is consistent with socioemotional selectivity theory, which holds that the open-ended time horizon of young adults allows them to pursue preparatory goals and, therefore, makes them more inclined to seek out new information; whereas older adults, to a greater extent, focus on information that is likely to support a positive emotional state and enhance well-being (e.g., Carstensen, Fung, \& Charles, 2003; Mather \& Carstensen, 2005).

\section{The Distribution of Emotionally Positive and Negative Memories Over The Life Span}

Studies on emotion and autobiographical memory in middleaged and older adults show that the accessibility of emotionally positive and negative events varies as a function of when in life the events took place: When people over 40 years old are asked to recall autobiographical memories cued by a sample of words (Rubin, Wetzler, \& Nebes, 1986) or just narrate their lives (Fitzgerald, 1988) there is an increase of memories from young adulthood, termed the reminiscence bump. At the same time, a number of studies have shown that the life span distributions of emotionally positive and negative events are dramatically different. When asked to nominate and date their most positive memories, a pronounced reminiscence bump is seen. However, the distribution of memories of negative events does not show such a peak in young adulthood. Instead negative events show a slow increase over the life span (Berntsen \& Rubin, 2002; Rubin \& Berntsen, 2003; see also Siegler \& George, 1983). Likewise when middle-aged and older participants are asked to nominate events that are "important" or "central to the life story" and only later judge the memories for emotional valence, positive, but not negative, life events show an increase in young adulthood (Berntsen \& Rubin, 2002; Bohn, 2010).

One likely explanation of these findings is that the accessibility of memories across the life span is influenced by cultural life scripts - that is, culturally shared representations of the timing of major transitional events (e.g., Berntsen \& Rubin, 2004; Neugarten, More, \& Lowe, 1965). Cultural life scripts are used in the processing and construction of personal life stories and are, therefore, central to autobiographical memory. They are measured by asking subjects to generate the events that are most likely to happen in a prototypical newborn baby's life (Berntsen \& Rubin, 2004). Research based on this method has shown life scripts to be strongly biased toward positive events that are expected to take place in young adulthood, such as childbirth and marriage (Berntsen \& Rubin, 2004). This finding has been replicated in different nationalities and cultures, such as Danish, Turkish, German, Dutch and American samples (Bohn, 2010; Erdoğan, Baran, Avlar, Cağlar Taş, \& Tekcan, 2008; Habermas, 2007; Janssen \& Rubin, 2010; Rubin, Berntsen, \& Hutson, 2009). Thus, culturally shared life scripts are likely to provide some of the explanation as to why autobiographical remembering is dominated by positive events, 
and why these memories are more likely to refer to events from young adulthood. Following the notion of life script, such events play a key role in the stories that we construct about our lives.

\section{Effects of Emotional Disorders on The Accessibility of Positive and Negative Memories}

Although the accessibility of autobiographical memories is generally biased in the favor of positive events, this bias is significantly reduced or even reversed in emotional disorders, such as depression. For example, depressed individuals recall fewer specific episodes in response to positive emotion words than in response to negative words and have longer retrieval times for the former than for the latter (Williams, 1992). Also, dysphoria significantly reduces the fading affect bias (Walker, Skowronski, Gibbons, Vogl, \& Thompson, 2003).

The accessibility of an event in memory to a large part depends on how well this event is integrated and connected with other memories and is, therefore, related to how central an event is perceived to be for the person's life story and identity as measured by the CES (Berntsen \& Rubin, 2006, 2007). Consistent with the view that the accessibility of negative events is enhanced in many emotional disorders, robust positive correlations have been found between the CES for negative events and level of PTSD symptoms in relation to the event (Berntsen \& Rubin, 2006, 2007, 2008; Boals, 2010; Robinaugh, \& McNally, 2010; Rubin, Boals, \& Berntsen, 2008; Rubin, Berntsen, \& Hutson, 2009; Schuettler \& Boals,2011; Smeets, Giesbrecht, Raymaekers, Shaw, \& Merckelbach, 2010; Thomsen \& Berntsen, 2009). This positive relationship has been found in a variety of populations suffering from different types of traumatic events. It persists in regression analyses controlling for such factors as depression, anxiety, dissociation, neuroticism, repressive coping, self-consciousness, and severity of the trauma (e.g., Berntsen \& Rubin, 2007; Rubin et al., 2008; Smeets et al., 2010). The CES also predicts other forms of distress than symptoms of PTSD, such as life interference and psychological distress due to chronic pain (Perri \& Keefe, 2008), complicated grief in response to loss (Boelen, 2009), and current depression, anxiety, and stress associated with an early shameful experience (Pinto-Gouveia \& Matos, 2011). In short, the accessibility of at least certain negative memories is systematically and positively related to measures of emotional disorders and/or emotional distress.

\section{Effects of Personality Traits on The Accessibility of Positive and Negative Memories}

There is a long tradition for relating positive versus negative affectivity to personality dimensions, especially extraversion and neuroticism (e.g., Gilboa \& Revelle, 1994). Neuroticism is associated with a predisposition to experience negative emotion as well as a tendency to ruminate about them. Thus, neuroticism is likely to enhance the accessibility of negative events in memory (Rubin, Berntsen, \& Bohni, 2008). This is consistent with findings showing that higher scores on a neuroticism scale are associated with more negative autobiographical recollections (Rubin, Boals, \& Berntsen, 2008; Rasmussen \& Berntsen, 2010) and with increased access to emotionally negative information, notably, emotionally negative information that is perceived as self-related (Martin,
1985; Teasdale \& Green, 2004). Because of its connection with rumination, neuroticism is also likely to foster narrative strategies that allow the negative affect associated with the event to influence the interpretation of other, more neutral, memories, such as in contamination stories as described by McAdams and colleagues (McAdams, Reynolds, Lewis, Pattern, \& Bowman, 2001). Extraversion, on the other hand, is generally associated with positive affectivity (e.g., Gilboa \& Revelle, 1994), and we should, therefore, expect this dimension to enhance the accessibility of positive autobiographical memories, consistent with some findings (Rubin, Boals, \& Berntsen, 2008; but see Rasmussen \& Berntsen, 2010).

\section{About The Present Study}

The goal of the present study is to further examine the effects of positive versus negative emotion on the long-term accessibility of autobiographical memories. In order to do so we compare the CES answered for a highly negative versus highly positive event in a large sample of older adults. The CES taps the extent to which a memory is seen as central to the person's life story and identity by asking questions such as "This event has become a reference point for the way I understand myself and the world", "This event permanently changed my life", and "I feel that this event has become part of my identity" (Berntsen \& Rubin, 2006). The CES was originally developed to examine the role of the traumatic memory for life story and identity in Posttraumatic Stress Disorder (PTSD), but can also be used as a general measure of the perceived self-relevance of autobiographical events and their centrality for life story and identity (e.g., Johannessen \& Berntsen, 2009; Johannessen \& Berntsen, 2010). Two studies (Boals, 2010; Rasmussen $\&$ Berntsen, 2009) have directly compared the CES for a highly negative versus highly positive event in populations of undergraduates and found no significant differences. However, it is unknown whether this finding can be generalized to older age groups, given the enhanced positivity bias among old compared to young individuals (e.g., Mather \& Carstensen, 2005) and given the fact that the accessibility of positive versus negative events shows large variations when viewed over the entire life course (Berntsen \& Rubin, 2002).

In the following we review our predictions as to how these two measures (a) differ overall; (b) differ with regard to their relation with other variables, notably measures of emotional distress, personality, and cultural norms for the organization of life story and identity; and (c) differ across the life span. We use the labels CES-negative and CES-positive to indicate the CES as answered for a self-nominated highly negative/traumatic and positive event, respectively.

Based on earlier work showing a dominance of positive relative to negative events in autobiographical remembering (e.g., Walker et al., 2003), and the fact that such tendency to focus on positive information is enhanced in old age (Mather \& Carstensen, 2005) we expect our participants in general to rate their self-nominated most positive event as more central to their self and identity than their most negative/traumatic event.

However, given the fact that such positivity bias is known to be absent (or significantly reduced) in emotional disorders such as depression and PTSD (e.g., Peterson \& Seligman, 1984; Watson, Dritschel, Jentzsch, \& Obonsawin, 2008; Walker et al., 2003; Williams, 1992) and given previous work has showed substantial 
correlations between CES-negative and PTSD, we would expect increasingly similar levels of CES-negative and CES-positive with increasing symptoms of distress related to a negative event.

We expect the CES-negative to be predicted by measures related to negative affectivity, notably neuroticism and measures of emotional distress. In contrast, we expect correspondence with cultural life script and (less reliably) extraversion to be a major predictor for the CES-positive. Following previous work on the relation between autobiographical memory and personality traits, we expect both centrality measures to be positively associated with openness (Rasmussen \& Berntsen, 2010).

Negative affect has been found to fade more rapidly over time than positive affect (e.g., Walker et al., 2003). Assuming that the emotional intensity of an event is related to its perceived centrality (Berntsen \& Bohn, 2010), we should expect the CES-negative to be higher for more recent events. To the extent the CES-positive is predicted by life script events, we should expect it to be higher for events from young adulthood, where life script events are especially common.

\section{Method}

The data for the present study were collected as a part of the University of North Carolina Alumni Heart Study (UNCAHS). The UNCAHS is an ongoing retrospective-prospective cohort study of participants who entered UNC Chapel Hill between 1964 and 1966. Participants were recruited to join the study in 1986-87 (Siegler et al., 1992) and their spouses were invited to join the study in 1992 (Brummett et al., 2000). Over the 12 waves of the study, response rates have been between 65 and $86 \%$. The current questionnaire, which was collected in 2008-2010, had psychosocial measures intended to predict coronary heart disease and related disease outcomes (Siegler, 2007) as well as the measures reported here. We also included personality inventories taken in 1988 and 1997 and a depression measure taken in 2007 because of the importance of these measures to PTSD symptoms.

\section{Participants}

Of the 4,612 who are active members of the UNCAHS in that they either responded to this questionnaire or one of the previous two questionnaires, which were given in 2004-5 and 2006-7, and who are not known to be deceased, 3,682 (80\%) returned questionnaires. We limited our analysis to the 3,389 who were in their sixties when they answered the questionnaire to provide a more uniform age range and, among those, to the 2,526 (74.5\%) who reported both a positive and negative event. Their mean age was 62.32 years $(S D=1.47)$, $69 \%$ were males, and $99 \%$ were Caucasian. They had a mean education level of $6.25(S D=1.47)$, where 6 is a college degree plus additional training and 7 is a masters degree; a mean family income of $7.06(S D=2.42)$, where 7 is $\$ 60,000$ to $\$ 69,999$; and a self-rated health score of 1.66 $(S D=0.62)$, where 1 is excellent, and 2 is good.

\section{Materials}

All measures included here were taken in the current wave, except for The NEO Personality Inventory and the Prime MD (see below).
Centrality of Event Scale-Negative (CES-negative). The CES-negative (Berntsen \& Rubin, 2006, 2007) measures the extent to which a traumatic memory forms a central component of personal identity, a turning point in the life story and a reference point for everyday inferences. We use the short version, which consists of 7 items rated on 5 point scales from 1 (totally disagree) to 5 (totally agree) in relation to the most stressful or traumatic event in the person's life. The mean rating is reported. The CES-negative is positively correlated with severity of PTSD symptoms, which remain significant when controlling for measures of anxiety, depression, dissociation, and self-consciousness (Berntsen \& Rubin, 2006, 2007).

Centrality of Event Scale-Positive (CES-positive). The Centrality of Event Scale (see above) as answered for a highly positive event measures the extent to which a self-nominated highly positive event forms a central component of personal identity, a turning point in the life story and a reference point for everyday inferences. We use the short version, which consists of 7 items rated on 5 point scales from 1 (totally disagree) to 5 (totally agree) in relation to the most positive event in the person's life. The mean rating is reported.

TLEQ. The Traumatic Life Events Questionnaire (TLEQ, Kubany et al., 2000) was developed as way of reminding people of possible traumas to get a more complete reporting of traumas by providing a series of 23 specific examples of possible traumas. We used these items but modified the first item, "Have you ever experienced a natural disaster (a flood, hurricane, earthquake, etc.)" by adding "for which you received medical attention or that badly injured or killed someone" taken from the second item about motor vehicle accidents, because of the high frequency of hurricanes in North Carolina. To allow more privacy in reporting and to reduce possible distress, we also combined the four items about sexual abuse to one item and we combined the items about miscarriage and abortion. This resulted in 19 questions. For each event, the participants answer questions about how often that type of event occurred, whether the A1 and A2 PTSD criteria were met (American Psychiatric Association), and the participant's age at the time of the most serious occurrence. At the end, participants indicate which of these events bothers them the most now.

The NEO Personality Inventory (NEO-PI and NEO-PIR). The NEO-PI (Costa \& McCrae, 1985) and NEO-PIR (Costa \& McCrae, 1992) are inventories of normal personality that index the Five Factor Model of Personality. Factors are calculated according to the formula in manual, which uses the same norm for men and women combined to provide $T$ scores (i.e., norms with a mean of 50 and a standard deviation of 10). The NEO-PI was administered in 1988 and the NEO-PIR in 1997. To increase reliability and minimize missing data, we averaged these scores (see Costa, Herbst, McCrae, \& Siegler, 2000, for a comparison of the forms and joint scoring) if both were present or used only one if that was all that was available. The measures of the five NEO personality traits showed high consistency across the two waves (the correlation coefficients were $N=.78, \mathrm{E}=.83, \mathrm{O}=.85, \mathrm{~A}=.84, \mathrm{C}=$ .83 , all $p \mathrm{~s}<.0001$, all $N \mathrm{~s}=1894)$.

Prime MD. Prime MD (Kroenke, Spitzer, \& Williams, 2001) is a 9 item version of the PHQ (patient health questionnaire) that is used to screen for depression. Symptoms over the past two weeks are rated from not at all to nearly every day. A score of $>$ 
$=11$ indicates major depressive disorder. This measure was taken in 2006-07.

PTSD Check List (PCL). The PCL (Weathers, Litz, Huska, $\&$ Keane, 1994) has participants rate the 17 official symptoms of PTSD, on a scale from 1 (not at all) to 5 (extremely). The minimum score is thus 17 .

Well-Being. This is indexed by a measure of happiness (Lyubomirsky \& Lepper, 1999) consisting of four questions rated on 7 point scales addressing how happy the person perceives himor herself to be in comparison to other people from 1 (not a very happy person) to 7 (a very happy person). It also includes a new measure which expands self-rated health to include self-ratings on five dimensions of importance at midlife (health, memory, coping, finances, and support, Siegler, 2004). Respondents are asked: How would you rate: Your current health? Your memory? Your ability to cope with stress? Your current financial well-being? The support you receive from persons close to you? Each item is rated on a 1 (excellent), 2 (good), 3 (fair), and 4 (poor) scale. (For the sake of clarity, we reverse these scores in the analyses).

\section{Procedure}

To start the data collection, a newsletter was sent to respondents explaining the purpose of the current questionnaire along with instructions to $\log$ on to the UNCAHS web site and answer the questionnaire on line. Individuals who did not respond online were sent an identical paper version that could be scanned upon arrival. Reminders were sent up to 3 times to maintain the response rate of this longitudinal study population. Questionnaires were designed to be completed in less than one hour of time to maintain a high response rate for each questionnaire and to ensure long-term participation in the study. About half of the participants responded to the web survey, and the other half responded on the mail survey.

After health status update questions and the well-being questions, information about the most negative event began with the TLEQ. Our previous work has shown a recency effect for the sampling of negative events across the life span, but not for the sampling of the positive events (Berntsen \& Rubin, 2002; Rubin \& Berntsen, 2003). We used the TLEQ in an attempt to counteract such effect and to ensure that our participants sample both types of events from their entire life. Once the event from the TLEQ categories "that bothers you the most now" was nominated, it was used for the CES-negative and then the PCL. Next we requested a one to two sentence description of "the most positive event in your life, the one that brings you the most pride or happiness now." We used this formulation to provide an emotionally positive counterpart to the negative event sampled by the TLEQ. The event was dated and followed by the CES-positive.

Scoring of correspondence with the cultural life script. Only positive events were coded for their correspondence with the cultural life script. A similar coding did not make sense for the traumatic events sampled through the TLEQ because only one of the TLEQ event categories (i.e., "the sudden and unexpected death of a close friend or loved one") might show correspondence with events listed in the American cultural life script (i.e., Others' death and Parents' death, cf. Rubin et al., 2009, Table 2), although the emphasis on the sudden and unexpected nature of the death renders correspondence with life script questionable. The positive events were first classified by an independent judge, blind to the theory and hypothesis of the present study, including the notion of life script. This initial classification was done as closely as possible to the text labels provided by the participants. It resulted in a list of 265 event categories. These categories were then coded for their overlap with the 24 events listed in the American life script (Rubin et al., 2009).

\section{Results}

Table 1 contains means and standard deviations of measures describing our sample. In the following we examine (a) how CES-negative and CES-positive relate to one another and to other measures, (b) which variables predict the two key measures, (c) how the CES-negative and CES-positive vary for events that have happened at different times in the life span, and (d) the life span distribution of the most positive and most negative events.

How CES-negative and CES-positive relate to one another and to other measures. As shown in Table 1, the overall mean for the CES-positive (3.98) was considerably higher than the overall mean for the CES-negative $(2.44), t(2,525)=52.94, p<$ .0001 . Since the rating scale ranges from 1 to 5 , the difference between the two means spans almost a third of the scale. This difference is consistent with previous studies showing a positivity bias in old age: Overall, the participants considered their selfnominated "most positive" event as being more central to their life story and identity than their self-nominated "most negative/ traumatic" event. Figure 1, a histogram of the mean scores of the CES-negative and CES-positive, further explores this difference. It shows two contrasting patterns, with a decrease in frequency as one goes from high to low scores for the CES-positive and from low to high scores for the CES-negative. This is consistent with the assumption that high centrality of positive events constitutes the norm in this population, whereas high centrality of negative events forms an exception.

Table 1 contains the correlations between CES-negative and CES-positive and variables related to trauma, personality and well-being. The CES-negative has clear positive correlations with symptoms of PTSD, trauma severity, and number of traumas over life, whereas CES-positive shows no relationship with these measures. CES-negative also correlates positively with neuroticism and openness, whereas CES-positive shows only a very weak (but significant) correlation with neuroticism, and no significant correlation with openness. The variables related to well-being show weak negative correlations with CES-negative and a few weak positive correlations with CES-positive. As expected, a significant (but weak) correlation was found between CES-positive and extraversion. In short, as predicted, CES-negative is systematically related to a number of measures of emotional distress, well-being, and neuroticism. However, the CES-positive appears to be generally unrelated to these measures.

A multiple regression analysis showed that CES-negative remained a significant predictor for level of PTSD symptoms (as measured by the PCL) when controlling for the other variables listed in Table 1. The regression equation in standardized beta weights for PCL, including all variables that were significant at the .05 level, was PCL $=.41$ CES-negative +.19 number-oftraumas +.15 primeMDdepr +.08 NEO-N -.11 cope -.07 happy -.06 support, r-square $=.46, n=2,028$. When the CESnegative was removed, the r-square dropped to .31 . 
Table 1

Means of Variables and Correlations With the CES-Negative and CES-Positive

\begin{tabular}{|c|c|c|c|c|c|}
\hline Variable & Mean & $S D$ & r-CES - & r-CES + & $N$ \\
\hline Gender $(\mathrm{M}=0, \mathrm{~F}=1)$ & 0.31 & 0.46 & $0.19^{\text {****** }}$ & $0.12^{* * * * *}$ & 2526 \\
\hline \multicolumn{6}{|l|}{ CES } \\
\hline CES-negative & 2.44 & 1.23 & 1.00 & $0.18^{* * * * * *}$ & 2526 \\
\hline CES-positive & 3.98 & 1.03 & $0.18^{* * * * *}$ & 1.00 & 2526 \\
\hline \multicolumn{6}{|l|}{ Trauma and event related } \\
\hline PCL & 22.76 & 8.86 & $0.55^{\text {******** }}$ & $0.07^{* * * * *}$ & 2493 \\
\hline primeMDdepr & 2.51 & 3.12 & $0.21^{* * * * *}$ & 0.01 & 2174 \\
\hline age-at-trauma & 38.87 & 16.64 & $0.06^{*}$ & -0.03 & 1767 \\
\hline age-at-pos.-event & 35.04 & 12.92 & -0.01 & $-0.24^{* * * * * *}$ & 2382 \\
\hline number-of-traumas & 6.10 & 6.18 & $0.28^{* * * * *}$ & 0.03 & 2526 \\
\hline A1-trauma & 0.41 & 0.49 & $0.22^{\text {*********⿲二丨匕 }}$ & 0.01 & 2526 \\
\hline A2-trauma & 0.37 & 0.48 & $0.33^{\text {******* }}$ & $0.08^{* * * * *}$ & 2526 \\
\hline \multicolumn{6}{|l|}{ Personality } \\
\hline NEO-N & 48.88 & 9.89 & $0.23^{* * * * *}$ & $0.06^{* *}$ & 2376 \\
\hline NEO-E & 49.54 & 9.54 & -0.03 & $0.07^{* *}$ & 2376 \\
\hline NEO-O & 53.13 & 10.64 & $0.14^{\text {******** }}$ & 0.02 & 2376 \\
\hline NEO-A & 47.81 & 9.59 & 0.03 & $0.09^{* * * * *}$ & 2376 \\
\hline NEO-C & 51.92 & 10.34 & -0.01 & 0.03 & 2376 \\
\hline \multicolumn{6}{|l|}{ Well-being } \\
\hline happy & 5.47 & 1.09 & $-0.16^{* * * * *}$ & $0.09^{* * * * *}$ & 2521 \\
\hline health & 3.34 & 0.62 & $-0.16^{* * * * * * *}$ & 0.00 & 2513 \\
\hline memory & 3.27 & 0.61 & $-0.11^{\text {******* }}$ & 0.00 & 2513 \\
\hline cope & 3.23 & 0.65 & $-0.18^{* * * * * *}$ & 0.02 & 2508 \\
\hline finance & 3.20 & 0.72 & $-0.12^{\text {******** }}$ & 0.01 & 2508 \\
\hline support & 3.49 & 0.66 & $-0.09^{* * * * * *}$ & $0.11^{* * * * * *}$ & 2506 \\
\hline
\end{tabular}

As shown in Table 1, CES-negative and CES-positive were weakly, but significantly, correlated. This is likely to reflect that both measures to some extent reflect an underlying tendency for self-focused attention (Ingram, 1990) that may have maladaptive consequences when applied to highly negative experiences, as measured by the CES-negative (e.g., Mor \& Winquist, 2002).

Figure 2 examines how the CES-negative and CES-positive vary with PTSD symptom severity. In order to construct Figure 2, participant scores on the PCL were put into bins of 5 units, starting at the lowest possible score of 17 , which results from a response of one on each of the 17 items. As there were fewer participants as the PCL scores increased, we combined scores from 47 to 56 into one bin of 56 participants and all scores over 56 in one bin of 32 participants. As expected from the correlations the CES-negative increases markedly with increasing levels of PTSD, whereas CES-

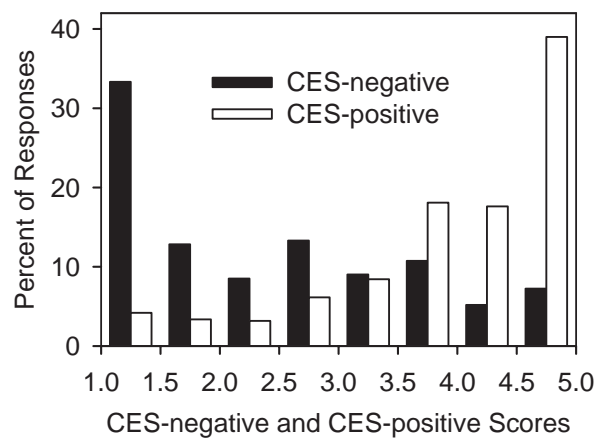

Figure 1. Percent of responses as a function of mean scores on the CES-negative and CES-positive. positive largely remains at the same level. Only at the high end of the PTSD scale do the mean scores of the CES-negative approach and exceed the mean scores of the CES-positive. A commonly used cutoff for the PCL to discriminate people who may have PTSD if they meet the other criteria is 44 (Blanchard, JonesAlexander, Buckley, \& Foneris, 1996), and this is about where the CES-negative approaches the same level as the CES-positive.

Variables predicting CES-negative and CES-positive. We conducted two multiple regression analyses, with CES-negative and CES-positive as the dependent measures, respectively. The predictor variables were the variables included in Table 1. For both analyses, we excluded age-at-trauma because it had more missing data than the other variables and reduced the number of participants whose data could be used. (The age data were more likely to

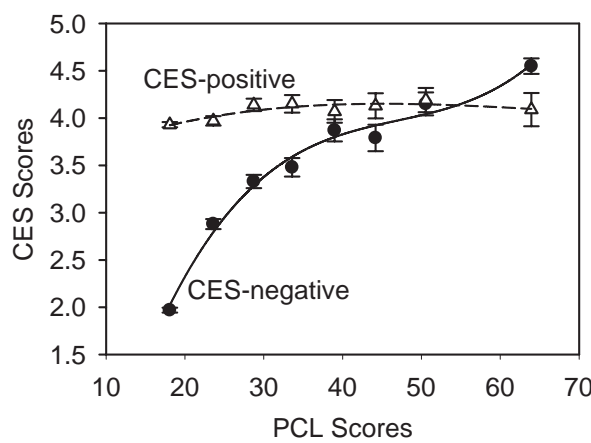

Figure 2. Mean scores on the CES-negative and CES-positive as a function of PCL scores. The error bars represent standard errors. 
be missing when the event was reported multiple times and only a range was given). When it was included, it had beta weights of .11 and -.06 in the CES-negative and CES-positive regressions. For the regression analyses predicting CES-positive we included a dichotomous variable indicating whether or not the event corresponded to an event category in the cultural life script as measured in an American sample (Rubin \& Berntsen, 2003), which will be described and analyzed in more detail later.

The regression equation in standardized beta weights for CESnegative, including all variables that were significant at the .05 level, was CES-negative $=.47 \mathrm{PCL}+.15 \mathrm{~A} 2$-trauma +.12 CES-positive +.10 A1-trauma +.07 gender +.05 number-oftraumas +.04 NEO-O, r-square $=.39, n=2,309$. The results of the regression analysis for CES-negative thus confirmed the robust relations between this measure and measures of PTSD symptoms, and trauma history (i.e., trauma severity measured in terms of the A1 and A2 trauma criteria and number of earlier traumas). In addition, CES-positive, female gender and NEO-Openness showed significant effects.

The regression equation for CES-positive was CES-positive = .25 life script correspondence +.17 CES-negative -.15 age-atpositive-event +.10 happy $+.10 \mathrm{NEO}-\mathrm{N}+.07$ support +.04 NEO-A, r-square $=.17, n=2,188$. If the life-script predictor were not included, the r-square value would drop to .11. The regression analysis for CES-positive thus showed that correspondence with life-script was an important predictor. It is noteworthy that measures of PTSD symptoms and trauma history were unrelated to CES-positive, and also that the r-square value is less than half as big as the one for CES-negative. Taking together the findings suggest that having emotionally positive events central to one's life may constitute a cultural default and is therefore is less influenced by factors related to individual differences.

How the CES-negative and CES-positive vary across the life span. Figure 3 shows the means of the CES-negative and CES-positive as a function of age at the time of the most positive and most negative event, respectively. As illustrated by the figure, and consistent with the regression analyses, people are less likely to judge their most positive event as central to life story and identity if it has taken place in the recent past compared to earlier in life, whereas the reverse is true for the self-nominated most negative events. Figure 3 also shows that the CES-positive is higher than CES-negative across all ages, except for the most

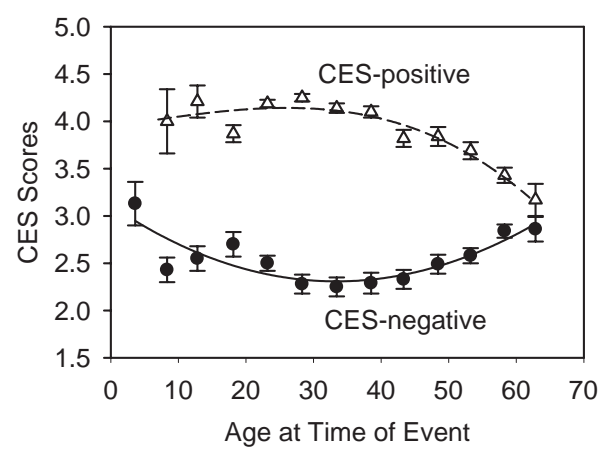

Figure 3. Mean scores on the CES-negative and CES-positive as a function of age at the time of the event. The error bars represent standard errors. recent past. These dissimilar life span distributions are consistent with the fact that the two measures have different predictors. One important predictor for CES-positive was correspondence with life script. As described earlier, life script events are especially frequent in young adulthood and thus more frequent earlier than later in life (Berntsen \& Rubin, 2004), which may help to explain why CES-positive drops with increasing age. CES-negative, on the other hand, was primarily predicted by current levels of PTSD symptoms and ratings of trauma severity. Following the mobilization-minimization hypothesis (Taylor, 1991) as well as the notion of the fading affect bias (Walker et al., 2003), the emotional, physiological, cognitive, and social response to a traumatic event would be more intense and cause more impact for negative events that have happened recently, as compared to earlier in life.

Life span distribution of the most positive and most negative events. To further understand the life span distribution of the CES-positive and CES-negative values, we examine the life span distributions of the events on which they were based. Figure 4 shows how the self-nominated most positive and most negative events are distributed across the life span. (To construct Figure 4, we calculated the percentage of positive and negative memories in each 5 -year bin up to age 60, which was the age of the youngest participant.)

Consistent with our earlier work, the most positive events are characterized by a marked dominance of events from young adulthood, peaking in the second decade of life. The frequency of the most negative events, on the other hand, does not have a large peak in young adulthood, but overall slowly increases with increasing age, corresponding to a monotonically decreasing retention function (Berntsen \& Rubin, 2002). One exception from this overall pattern is a small peak for the negative events from the years 20-24, which appears to be a cohort effect: Over half the increase from years 20 to 24 in this Vietnam Era population is caused by the greater proportion of traumas from two TLEQ categories. Combat accounted for 3.52 of the $11.36 \%$ shown in that five year period and sudden death of a close friend or loved one accounted for 3.19\%. Except for this cohort effect, the distributions are largely similar to those found earlier for emotionally positive versus negative events (Berntsen \& Rubin, 2002; Rubin \& Berntsen, 2003).

Previous studies examining self-nominated highly positive and highly negative events (e.g., Berntsen \& Rubin, 2002; Rubin \& Berntsen, 2003) did not examine the content. An analysis of the content helps to explain the dissimilar life span distribution (see Figure 4). The most frequently mentioned negative events were "unexpected death of close friend or loved one" $(31.9 \%)$, and "life threatening illness" (16.2\%), accounting for almost half of the reported events. These events are in general more likely to take place later than earlier in life. The other reported events were distributed according to the remaining 17 event categories in the TLEQ in the following way: loved one survived life-threatening accident, illness or attack $(8.6 \%)$, motor vehicle accident $(6.8 \%)$, warfare/combat $(4.3 \%)$, nonlive birth $(4.1 \%)$, natural disaster $(3.5 \%)$, observing family violence $(3.4 \%)$, sexual abuse $(2.5 \%)$, other accident $(2.3 \%)$, being robbed $(1.6 \%)$, spouse/partner abuse $(1.2 \%)$, someone threatened to kill you (1.1), being physically punished (1.0\%), observing attack by stranger (1.0\%), being hurt by stranger 


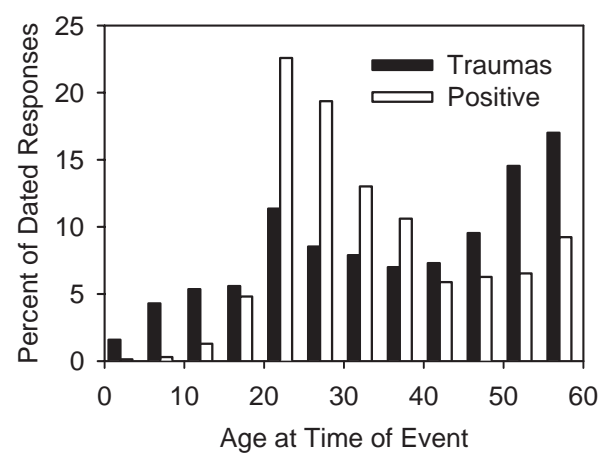

Figure 4. Percent of traumas and positive events as a function of age at the time of the event.

$(0.9 \%)$, been stalked $(0.6 \%)$, other event not mentioned $(6.7 \%)$, event that one cannot talk about $(2.2 \%)$.

The majority of the positive events, on the other hand, dealt with events in the cultural life script as measured in an American sample (Rubin et al., 2009). When the most positive events were classified in accordance with the 24 event categories in the American life script, $68 \%$ referred to life script events. In the rank order of the frequencies, the life script events were: Having children $(34.2 \%)$, marriage $(22.0 \%)$, college $(5.8 \%)$, birth of grandchildren $(3.2 \%)$, fall in love $(3.0 \%)$, retirement $(0.9 \%)$, first job $(0.7 \%)$, settle on career $(0.5 \%)$, high school $(0.2 \%)$. As illustrated by Figure 5, life script events expected to take place in young adulthood accounted for the great majority of all positive events and explained the reminiscence bump for the positive events in Figure 4.

\section{Discussion}

Overall the findings show that highly positive and highly negative events relate markedly differently to life story and identity. This has important implications for our understanding of the effects of emotional valence on autobiographical memory as well as for our understanding of emotional distress, such as PTSD. We found that self-nominated highly positive events were generally judged to be considerably more central to life story and identity than were self-nominated highly negative events, consistent with previous work showing a pronounced positivity bias in autobiographical memory in general (Walker et al., 2003) and in old age in particular (e.g., Mather \& Carstensen, 2005). However, with increasing levels of PTSD symptoms the CES-negative approached, and in extreme cases even exceeded, the CES-positive. We also found that the CES-negative and CES-positive were differently related to almost all measures of emotional distress, well-being and personality. The CES-negative was a major predictor of current level of PTSD symptoms also when controlling for a number of previous trauma, well-being and personality measures. The CES-positive, on the other hand, was largely unrelated to measures of PTSD, measures of other forms of emotional distress as well as measures of personality. The CES-negative had many significant predictors, which together accounted for a substantial part of the variance related to this measure. The most important predictors were level of PTSD symptoms, and the severity of the previous traumas (measured in terms of the A1 and
A2 trauma criteria from the PTSD diagnosis, American Psychiatric Association, 2000). The CES-positive, on the other hand, had fewer predictors, accounting for less of the variance. The most important one was whether or not the positive event corresponded to an event category in the cultural life script.

Cultural life scripts and the centrality of positive and negative events. The fact that life script correspondence was a significant predictor for the centrality ratings of the positive events may help to explain why the CES-positive showed fewer and less clear associations with other measures of individual differences than did the CES-negative. The reason may be that CES-positive to a greater extent than CES-negative reflects a cultural default for the structuring of life story and identity. As demonstrated by Berntsen and Rubin (2004), cultural life scripts are biased in the favor of positive events happening in young adulthood. Consistent with these observations, the frequency of positive events in the present study peaked markedly in the third and fourth decade of life, which together accounted for more than $60 \%$ of the positive events. In contrast, the negative events were distributed quite uniformly across most of the life span but showed a linear increase from age 40 to the respondents' current age, as has also been found in earlier work (Berntsen \& Rubin, 2002; Rubin \& Berntsen, 2003). The majority of the positive events dealt with highly typical life script events. Indeed, $56 \%$ of the respondents came up with the same two events-marriage and childbirth. These events are ranked as 1 and 2 on the American life script (see Rubin et al., 2009). When the life span distribution of the positive events was broken down by correspondence versus no correspondence to the life script, we found that only positive events with correspondence to life script formed a bump (also see Bohn, 2010). These findings suggest that many of the respondents have used their cultural life script as their guidance in relation to nominating a "most positive" event. Such life script consistent events helps to anchor the personal life story in a cultural context and are often used as concrete turning points in life stories defining beginning and endings of life story chapters (e.g., Thomsen, Pillemer, \& Ivcevic, 2011).

The finding that the means of the CES-negative approached (and even exceeded) the means for CES-positive with increasing levels of PTSD symptoms suggests that highly negative and/or traumatic life events challenge this default and form an alternative, less positive and less normative interpretation of life. Likewise, the fact that the CES-negative correlated positively with trauma se-

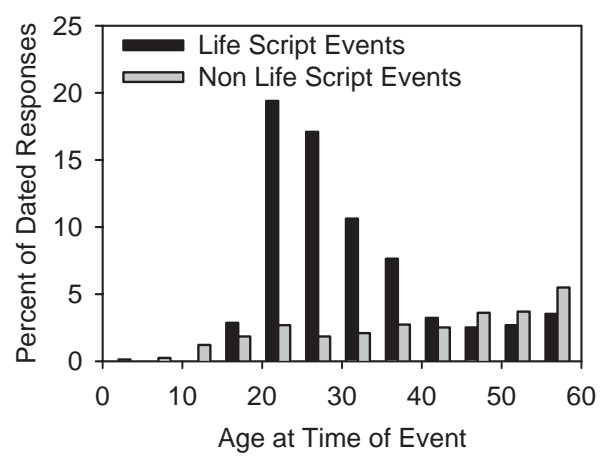

Figure 5. Percent of positive life script events and positive nonlife script events as a function of age at the time of the event. 
verity and number of previous traumas suggests that the person's trauma history (as evaluated retrospectively) contributes to such schema-deviant and non-normative life-story and selfconstruction. The correlations between CES-negative and NEOOpenness and NEO-Neuroticism suggest that individuals with higher scores on these dimensions are more likely to engage in such non-normative construction of life story and identity. Taken together these findings may be summarized in terms of a positivity bias that uses culturally normative positive events as a default for the schema-based structuring of life story and identity. This bias is reduced in emotional disorders especially when faced with the challenges of extreme negative events as in PTSD.

Centrality of positive and negative events across the life span. When the means for the CES-positive and CES-negative were plotted as a function of age at the time of the most negative and most positive event, respectively, the CES-positive dropped with increasing age whereas the CES-negative tended to increase with increasing age. Thus, the positive events in the recent past were not rated as central to life story and identity as were the positive events earlier in life, whereas the negative events tended to show the reverse pattern with recent events being rated as more central than remote events (with the exception of traumatic experiences in early childhood which stayed at a high level; Figure 3). The increase shown for the CES-positive with increasing distance to the event is likely to reflect the effects of cultural life scripts, according to which earlier periods in life, especially young adulthood, are associated with more positive events than later periods in life. Nostalgia and other forms of idealization of the past may also play a role (Field, 1981; Holbrook, 1993; Taylor, 1991; Wilson \& Ross, 2003).

One possible explanation of the pattern for CES-negative across the life span is the mobilization-minimization thesis (Taylor, 1991), according to which negative life events cause an immediate mobilization in terms of strong physiological, cognitive, emotional, and social responses. This mobilization of the organism is followed by responses that serve to minimize the long-term impact of that event, consistent with a general positivity bias (Matlin \& Stang, 1978; Taylor \& Brown, 1988). This thesis is consistent with multiple studies showing that the emotional content of negative events fade more quickly over time than the emotional content of positive events (see Walker et al. 2003, for review). Because centrality to life story and identity is positively related to level of emotion associated with the event (Berntsen \& Bohn, 2010) we would expect the CES-negative to be higher for the most recent events, consistent with the findings.

Two previous studies (Boals, 2010; Rasmussen \& Berntsen, 2009) compared the CES-negative and the CES-positive and found no differences. However, in contrast to the present study, both of these studies involved undergraduates and, therefore, concerned events of a more recent date than the ones analyzed in the present study with older adults, who sampled events across the entire life span. As in these previous studies with undergraduates, our analyses showed no differences between the CES-negative and CESpositive for events that had occurred in the most recent decade. It, therefore, seems that this difference is present only when the centrality is examined at a substantial temporal distance to the emotional events, suggesting a key role for retrospective evaluation. In addition, it is possible that the marked difference between the overall means of the CES-negative and CES-positive that was seen in the present study, but not in studies involving undergraduates, reflects a positivity bias that is not fully developed in young adulthood. This is consistent with studies showing that older compared to younger participants recall less emotionally negative events and more positive events (Kennedy et al., 2004; Schlagman et al., 2006) and have lower scores on measures of both frequency and intensity of negative affect (see Charles \& Carstensen, 2010; Charles, Reynolds, \& Gatz, 2001; de Vries, Blando, Southard, \& Bubeck, 2001, and Mroczek, 2001, for reviews). Following both explanations, the overall difference between the two measures that we found in the present study may be seen only when averaged for events across the entire life span in a middle-aged or older sample. Future research should examine how the relation between the CES-negative and the CES-positive develops over life and varies between different age groups.

Limitations. The following limitations should be considered when evaluating the present findings. First, the negative and positive events were sampled in different ways. For the sampling of the negative events we used a standardized questionnaire with 19 trauma event categories. We did so in order to remind the participants of possible traumas that they might have had during their lifetime to counteract a dominance of recent negative events as observed in earlier work, using free recall (Berntsen \& Rubin, 2002). In addition, the traumatic life event questionnaire included both a category of "other" events as well as a category of "experiences like these that you feel you can't tell about", allowing an open response to be made. The positive events, on the other hand, were sampled through free recall. This method was employed in order to avoid boosting the frequency of cultural life script events. Had the participants instead been probed with a list of typical positive life events (as an equivalent to the trauma questionnaire) life scripts events (such as marriage, having children, graduation) would most likely have been cued, making their observed high frequency difficult to interpret. Thus, the different instructions worked against the observed effects.

Only the positive events were coded for life script correspondence. Such a coding did not make sense in relation to the negative events as sampled through the TLEQ. Just one TLEQ event (i.e., "the sudden and unexpected death of a close friend or loved one") showed some correspondence with events listed in the American cultural life script (i.e., Others' death and Parents' death, cf. Rubin et al., 2009, Table 2), although it is not scripted in the sense of being locked to a particular time in life, given the emphasis on its sudden and unexpected nature (Berntsen \& Rubin, 2004). The sudden death category accounted for $32 \%$ of the negative events.

Second, because the present study was part of an ongoing longitudinal study, not all of our measures were taken at the same time, some derive from earlier waves. Measures of depressive symptoms were taken approximately 3 years earlier and measures of personality were averaged across scores obtained 12 years and 18 years ago. While we have evidence that these two measures are reasonably stable over time (see Costa et al., 2000), it is nonetheless the case that the effects personality and depression might have been higher if these measures were taken at the same time as the other measures. However, the key measures in the present study (the CES-negative and CES-positive, measures of PTSD symptoms, trauma- and well-being indicators) all derive from the same wave of data-collection. 
Third, it should also be noted that some of the present findings may be reflect cohort effects. In our analyses, we included only those respondents who were in the decade of the 1960s and who thus were born between 1940 and 1949. This implies that some of the male respondents fought in the Vietnam War, and that many of our respondents may have been otherwise affected by this war (e.g., waiting for their spouse to come home). It is not clear to which extent such cohort events have influenced the responses. However, the small peak of traumatic events in the age period of 20-25 (see Figure 4) corresponds to the time of the Vietnam War and appears, at least in part, to have been caused by the impact of this war on our respondents' lives.

Concluding comments. In a broader perspective, our findings help to resolve a dispute concerning the effects of negative and positive emotion on memory (e.g., Baumeister, Bratslavsky, Finkenauer, Vohs, 2001; Walker et al., 2003). Whereas many studies suggest that negative events cause greater physiological and affective reaction and more cognitive processing (Baumeister et al., 2001; Taylor, 1991) - which would enhance memory-positive events, on the other hand, appear to be more easily accessed on a long-term basis. As reviewed in the introduction, they tend to be retrieved more quickly than negative events and they are normally twice as frequent as negative events in free recall. Our findings help to resolve this paradox in the following way. Positive life events may mostly gain centrality (and thus long-term accessibility) through their correspondence with cultural norms. Negative events, on the other hand, may become central by deviating from cultural norms and by causing disruption and strong affective reactions, all of which associated with emotional distress. Following this view, positive and negative events both have highly powerful effects on memory and identity but through very different mechanisms. Negative events cause an immediate mobilization (Taylor, 1991), which may lead to long-term distress if not dampened down, whereas positive events help to anchor the person's life story and identity in the cultural norms of his or her society, which may serve as a buffer against emotional distress.

\section{References}

American Psychiatric Association. (2000). Diagnostic and statistical manual of mental disorders (4th ed., text revision). Washington, DC: Author.

Baumeister, R. F., Bratslavsky, E., Finkenauer, C., \& Vohs, K. D. (2001). Bad is stronger than good. Review of General Psychology, 5, 323-370. doi:10.1037/1089-2680.5.4.323

Berntsen, D. (2002). Tunnel memories for autobiographical events: Central details are remembered more frequently from shocking than from happy experiences. Memory \& Cognition, 30, 1010-1020. doi:10.3758/ BF03194319

Berntsen, D., \& Bohn, A. (2010). Remembering and forecasting. The relation between autobiographical memory and episodic future thinking. Memory \& Cognition, 38, 265-278. doi:10.3758/MC.38.3.265

Berntsen, D., \& Rubin, D. C. (2002). Emotionally charged autobiographical memories across the lifespan: The recall of happy, sad, traumatic, and involuntary memories. Psychology and Aging, 17, 636-652. doi: 10.1037/0882-7974.17.4.636

Berntsen, D., \& Rubin, D. C. (2004). Cultural life scripts structure recall from autobiographical memory. Memory \& Cognition, 32, 427-442. doi:10.3758/BF03195836

Berntsen, D., \& Rubin, D. C. (2006). Centrality of Event Scale. A measure of integrating a trauma into one's identity and its relation to Post-
Traumatic Stress Disorder Symptoms. Behaviour Research and Therapy, 44, 219-231.

Berntsen, D., \& Rubin, D. C. (2007). When a trauma becomes a key to identity: Enhanced integration of trauma memories predicts posttraumatic stress disorder symptoms. Applied Cognitive Psychology, 21, 417-431. doi:10.1002/acp.1290

Berntsen, D., \& Rubin, D. C. (2008). The Reappearance Hypothesis Revisited: Recurrent involuntary memories after traumatic events and in everyday life. Memory \& Cognition, 36, 449-460. doi:10.3758/ MC.36.2.449

Blanchard, E. B., Jones-Alexander, J., Buckley, T. C., \& Foneris, C. A. (1996). Psychometric properties of the PTSD checklist (PCL). Behaviour, Research and Therapy, 34, 669-673. doi:10.1016/00057967(96)00033-2

Boals, A. (2010). Events that have become central to identity: Gender differences in the centrality of event scale for positive and negative events. Applied Cognitive Psychology, 24, 107-121. doi:10.1002/ acp. 1548

Boelen, P. A. (2009). The centrality of a loss and its role in emotional problems among bereaved people. Behaviour Research and Therapy, 47, 616-622. doi:10.1016/j.brat.2009.03.009

Bohn, A. (2010). Generational differences in cultural life scripts and life story memories of younger and older adults. Applied Cognitive Psychology, 24, 1324-1345. doi:10.1002/acp.1641

Bohn, A., \& Berntsen, D. (2007). Pleasantness bias in flashbulb memories: Positive and negative flashbulb memories of the fall of the Berlin wall. Memory \& Cognition, 35, 565-577. doi:10.3758/BF03193295

Bradley, M. M., Greenwald, M. K., Petry, M. C., \& Lang, P. J. (1992). Remembering pictures: Pleasure and arousal in emotion. Journal of Experimental Psychology. Learning, Memory \& Cognition, 18, 379390. doi:10.1037/0278-7393.18.2.379

Brummett, B. H., Barefoot, J. C., Feaganes, J. R., Yen, S., Bosworth, H. B., Williams, R. B., \& Siegler, I. C. (2000). Hostility in marital dyads: Associations with depressive symptoms. Journal of Behavioral Medicine, 23, 95-105. doi:10.1023/A:1005424405056

Carstensen, L. L., Fung, H. H., \& Charles, S. T. (2003). Socioemotional selectivity theory and emotion regulation in the second half of life. Motivation and Emotion, 27, 103-123. doi:10.1023/A:1024569803230

Charles, S. T., \& Carstensen, L. L. (2010). Social and emotional aging. Annual Review of Psychology, 61, 383-409. doi:10.1146/annurev.psych .093008 .100448

Charles, S. T., Reynolds, C. A., \& Gatz, M. (2001). Age related differences and change in positive and negative affect over 23 years. Journal of Personality and Social Psychology, 80, 136-151. doi:10.1037/00223514.80.1.136

Costa, P. T., Jr., Herbst, J. H., McCrae, R. R., \& Siegler, I. C. (2000). Personality at midlife: Stability, intrinsic maturation, and response to life events. Assessment, 7, 365-378. doi:10.1177/107319110000700405

Costa, P. T., Jr., \& McCrae, R. R. (1985). The NEO Personality inventory manual. Odessa, FL: Psychological Assessment Resources.

Costa, P. T., Jr., \& McCrae, R. R. (1992). Revised NEO Personality Inventory (NEO PI-R) and NEO Five-Factor Inventory (NEO-FFI) Professional Manual. Lutz, FL: Psychological Assessment Resources.

de Vries, B., Blando, J. Southard, P., \& Bubeck, C. (2001). The times of our life. In G. Keyon, P. Clark, \& B. de Vries (Eds.), Narrative gerontology. Theory, research and Practice (pp. 137-158). New York: Springer.

Erdoğan, A., Baran, B., Avlar, B., Cağlar Taş, A., \& Tekcan, A. I. (2008). On the persistence of positive events in life scripts. Applied Cognitive Psychology, 22, 95-112. doi:10.1002/acp.1363

Field, D. (1981). Retrospective reports by healthy intelligent elderly people of personal events of their adult lives. International Journal of Behavioral Development, 4, 77-97.

Fitzgerald, J. M. (1988). Vivid memories and the reminiscence phenome- 
non: The role of a self narrative. Human Development, 31, 261-273. doi: $10.1159 / 000275814$

Fredrickson, B. L., \& Branigan, C. (2005). Positive emotions broaden the scope of attention and thought-action repertoires. Cognition \& Emotion, 19, 313-332. doi:10.1080/02699930441000238

Gilboa, E., \& Revelle, W. (1994). Personality and the structure of affective responses. In S. H. M. van Goozen, N. E. van de Poll, \& J. A. Sergeant (Eds.), Emotions: Essays on emotion theory (pp. 135-159). Hillsdale, NJ: Erlbaum.

Habermas, T. (2007). How to tell a life: The development of the cultural concept of biography. Journal of Cognition and Development, 8, 1-31.

Holbrook, M. B. (1993). Nostalgia and consumption preferences: Some emerging patterns of consumer tastes. Journal of Consumer Research, 20, 245-256. doi:10.1086/209346

Holland, A. C., \& Kensinger, E. A. (2010). Emotion and autobiographical memory. Physics of Life Reviews, 7, 88-131. doi:10.1016/j.plrev 2010.01 .006

Ingram, R. E. (1990). Self-focused attention in clinical disorders: Review and a conceptual model. Psychological Bulletin, 107, 156-176. doi: 10.1037/0033-2909.107.2.156

Janssen. S. M., \& Rubin, D. C. (2010). Age effects in cultural life scripts. Applied Cognitive Psychology, 24, 1-13.

Johannessen, K. B., \& Berntsen, D. (2009). Motivation for weight loss affects recall from autobiographical memory in dieters. Memory, 17, 69-83. doi:10.1080/09658210802555616

Johannessen, K. B., \& Berntsen, D. (2010). Current concerns in involuntary and voluntary autobiographical memories. Consciousness \& Cognition, 19, 847-860. doi:10.1016/j.concog.2010.01.009

Kennedy, Q., Mather, M., \& Carstensen, L. L. (2004). The role of motivation in the age-related positivity effect in autobiographical memory. Psychological Science, 15, 208-213. doi:10.1111/j.0956-7976.2004 $.01503011 . \mathrm{x}$

Kensinger, E. A., \& Schacter, D. L. (2006). When the Red Sox shocked the Yankees: Comparing negative and positive memories. Psychonomic Bulletin and Review, 13, 757-763. doi:10.3758/BF03193993

Kroenke, K., Spitzer, R. L., \& Williams, J. B. (2001). The PHQ-9. Validity of a brief depression severity measure. Journal of General Internal Medicine, 16, 606-613. doi:10.1046/j.1525-1497.2001.016009606.x

Kubany, E. S., Haynes, S. N., Leisen, M. B., Owens, J. A., Kaplan, A. S., Watson, S. B., \& Burns, K. (2000). Development and preliminary validation of a brief broad spectrum measure of trauma exposure: The Traumatic Life Events Questionnaire. Psychological Assessment, 12, 210-224. doi:10.1037/1040-3590.12.2.210

Lishman, W. A. (1974). The speed of recall of pleasant and unpleasant experiences. Psychological Medicine, 4, 212-218. doi:10.1017/ S0033291700042045

Lyubomirsky, S., \& Lepper, H. S. (1999). A measure of subjective happiness: Preliminary reliability and construct validation. Social Indicators Research, 46, 137-155. doi:10.1023/A:1006824100041

Martin, M. (1985). Neuroticism as a predictor toward depression: A cognitive mechanism. Personality and Individual Differences, 6, 353-365.

Mather. M., \& Carstensen, L. L. (2005). Aging and motivated cognition: The positivity effect in attention and memory. Trends in Cognitive Sciences, 9, 496-502. doi:10.1016/j.tics.2005.08.005

Matlin, M., \& Stang, D. (1978). The Pollyanna Principle. Selectivity in language, memory, and thought. Cambridge: Schenkman.

McAdams, D. P., Reynolds, J., Lewis, M., Pattern, A. H., \& Bowman, P. J. (2001). When bad things turn good and good things turn bad: Sequences of redemption and contamination in life narrative and their relation to psychosocial adaptation in midlife adults and in students. Personality and Social Psychology Bulletin, 27, 474-485. doi:10.1177/ 0146167201274008

Mor, N., \& Winquist, J. (2002). Self-focused attention and negative affect:
A meta-analysis. Psychological Bulletin, 128, 638-662. doi:10.1037/ 0033-2909.128.4.638

Mroczek, D. K. (2001). Age and emotion in adulthood. Current Directions in Psychological Science, 10, 87-90. doi:10.1111/1467-8721.00122

Neugarten, B. L., Moore, J. W., \& Lowe, J. C. (1965). Age norms, age constraints, and adult socialization. The American Journal of Sociology, 70, 710-717. doi:10.1086/223965

Perri, L. M., \& Keefe. F. J. (2008). Applying centrality of event to persistent pain: A preliminary view. Journal of Pain, 9, 265-271. doi:10.1016/j.jpain.2007.10.019

Peterson, C., \& Seligman, M. E. (1984). Causal explanations as a risk factor for depression: Theory and evidence. Psychological Review, 91, 347-374. doi:10.1037/0033-295X.91.3.347

Pinto-Gouveia, J., \& Matos, M. (2011). Can shame memories become key to identity? The centrality of shame memories predicts psychopathology. Applied Cognitive Psychology, 15, 281-290. doi:10.1002/acp.1689

Rasmussen, A. S., \& Berntsen, D. (2009). Emotional valence and the functions of autobiographical memories: Positive and negative memories serve different functions. Memory \& Cognition, 37, 477-492. doi: 10.3758/MC.37.4.477

Rasmussen, A. S., \& Berntsen, D. (2010). Personality traits and autobiographical memory: Openness is positively related to the experience and usage of recollections. Memory, 18, 774-786. doi:10.1080/ 09658211.2010 .514270

Reisberg, D., Heuer, F., McLean, J., \& O'Shaughnessy, M. (1988). The quantity, not the quality, of affect predicts memory vividness. Bulletin of the Psychonomic Society, 26, 100-103.

Robinaugh, D. J., \& McNally, R. J. (2010). Autobiographical memory for shame or guilt provoking events: Association with psychological symptoms. Behaviour Research and Therapy, 48, 646-652. doi:10.1016/ j.brat.2010.03.017

Rubin, D. C., \& Berntsen, D. (2003). Life scripts help to maintain memories of highly positive, but not highly negative, events. Memory \& Cognition, 31, 1-14. doi:10.3758/BF03196077

Rubin, D. C., Berntsen, D., \& Bohni, K. M. (2008). A memory based model of Posttraumatic Stress Disorder: Evaluating basic assumptions underlying the PTSD diagnosis. Psychological Review, 115, 985-1011. doi:10.1037/a0013397

Rubin, D. C., Berntsen, D., \& Hutson, M. (2009). The normative and the personal life: Individual differences in life scripts and life story events among USA and Danish undergraduates. Memory, 17, 54-68. doi: $10.1080 / 09658210802541442$

Rubin, D. C., Boals, A., \& Berntsen, D. (2008). Memory in Posttraumatic Stress Disorder: Properties of voluntary and involuntary, traumatic and non-traumatic autobiographical memories in people with and without PTSD symptoms. Journal of Experimental Psychology: General, 137, 591-614. doi:10.1037/a0013165

Rubin, D. C., Wetzler, S. E., \& Nebes, R. D. (1986). Autobiographical memory across the adult lifespan. In D. C. Rubin (Ed.), Autobiographical memory (pp. 202-221). New York: Cambridge University Press. doi:10.1017/CBO9780511558313.018

Schlagman, S., Schulz, J., \& Kvavilashvili, L. (2006). A content analysis of involuntary autobiographical memories: Examining the positivity effect in old age. Memory, 14, 161-175. doi:10.1080/09658210544000024

Schuettler, D., \& Boals, A. (2011). The path to posttraumatic growth versus PTSD: Contributions of event centrality and coping. Journal of Loss and Trauma, 15, 518-533.

Siegler, I. C. (2004). Middle Age Concerns Scale. Developed for UNC Alumni Heart Study. Durham, NC: UNC Alumni Heart Study Laboratory at Behavioral Medicine Research Center, Duke University.

Siegler, I. C. (2007, August). Psychology of aging and the public health. 2007 Developmental Health Award, Divisions 20 and 38. Invited address at the meetings of the American Psychological Association, San Francisco, California. 
Siegler, I. C., \& George, L. K. (1983). Sex differences in coping and perceptions of life events. Journal of Geriatric Psychiatry, 16, 197-209.

Siegler, I. C., Peterson, B. L., Barefoot, J. C., Harvin, S. H., Dahlstrom, W. G., Kaplan, B. H., . . Williams, R. B. (1992). Using college alumni populations in epidemiologic research: The UNC Alumni Heart Study. Journal of Clinical Epidemiology, 45, 1243-1250. doi:10.1016/08954356(92)90165-J

Smeets, T., Giesbrecht, T., Raymaekers, L., Shaw, J., \& Merckelbach, H. (2010). Autobiographical integration of trauma memories and repressive coping predict post-traumatic stress symptoms in undergraduate students. Clinical Psychology and Psychotherapy, 17, 211-218.

Talarico, J. M., Berntsen, D., \& Rubin, D. C. (2009). Positive emotions enhance recall of peripheral details. Cognition and Emotion, 23, 380398. doi:10.1080/02699930801993999

Talarico, J. M., LaBar, K. S., \& Rubin, D. C. (2004). Emotional intensity predicts autobiographical memory experience, Memory \& Cognition, 32, 1118-1132. doi:10.3758/BF03196886

Taylor, S. E. (1991). Asymmetrical effects of positive and negative events: The mobilization-minimization hypothesis. Psychological Bulletin, 111, 67-85. doi:10.1037/0033-2909.110.1.67

Taylor, S. E., \& Brown, J. D. (1988). Illusion and well-being: A social psychological perspective on mental health. Psychological Bulletin, 103, 193-210. doi:10.1037/0033-2909.103.2.193

Teasdale, J. D., \& Green, H. A. C. (2004). Ruminative self-focus and autobiographical memory. Personality and Individual Differences, 36, 1933-1943. doi:10.1016/j.paid.2003.08.022

Thomsen, D. K., \& Berntsen, D. (2009). The Long-term impact of emotionally stressful events on memory characteristics and life story. Applied Cognitive Psychology, 23, 579-598. doi:10.1002/acp.1495

Thomsen, D. K., Pillemer, D. B., \& Ivcevic, Z. (2011). Life story chapters, specific memories and the reminiscence bump. Memory, 267-279. doi: $10.1080 / 09658211.2011 .558513$
Walker, R. W., Skowronski, J. J., Gibbons, J. A., Vogl, R. J., \& Ritchie, T. D. (2009). Why people rehearse their memories: Frequency of use and relations to the intensity of emotions associated with autobiographical memories. Memory, 17, 760-773. doi:10.1080/09658210903107846

Walker, R. W., Skowronski, J. J., Gibbons, J. A., Vogl, R. J., \& Thompson, C. P. (2003). On the emotions that accompany autobiographical memories: Dysphoria disrupts the fading affect bias. Cognition and Emotion, 17, 703-723. doi:10.1080/02699930302287

Walker, R. W., Skowronski, J. J., \& Thompson, C. P. (2003). Life is pleasant-and memory helps to keep it that way. Review of General Psychology, 7, 203-210. doi:10.1037/1089-2680.7.2.203

Walker, W. R., Vogl, R. J., \& Thompson, C. P. (1997). Autobiographical memory: Unpleasantness fades faster than pleasantness over time. Applied Cognitive Psychology, 11, 399-413. doi:10.1002/(SICI)10990720(199710)11:5<399::AID-ACP462>3.0.CO;2-E

Watson, L. A., Dritschel, B., Jentzsch, I., \& Obonsawin, M. C. (2008) Changes in the relationship between self-reference and emotional valence as a function of dysphoria. British Journal of Psychology, 99, 143-152. doi:10.1348/000712607X248689

Weathers, F. W., Litz, B. T., Huska, J. A., \& Keane, T. M. (1994). The $P T S D$ checklist $(P C L)$, Unpublished scale available from the National Center for PTSD.

Williams, J. M. G. (1992). Autobiographical memory and emotional disorders. In S.-A Christianson (Ed.), The handbook of emotion and memory. Research and theory (pp. 451-477). Hillsdale, NJ: Erlbaum.

Wilson, A. E., \& Ross, M. (2003). The identity function of autobiographical memory: Time is on our side. Memory, 11, 137-149. doi:10.1080/ 741938210

Received June 24, 2010

Revision received May 24, 2011

Accepted June 8, 2011 